\title{
Mass Media as a Remedy for Poverty of the Stimulus in the Foreign Language Context
}

\author{
Samaneh Tarighat \\ Department of Foreign Languages, Islamic Azad University Tehran-North Branch, PO box 19615-451, Tehran, Iran \\ E-mail: s_tarighat@iau-tnb.ac.ir
}

Received: 12-05-2016

Published: 01-11-2016
Accepted: 31-07-2016

doi:10.7575/aiac.ijalel.v.5n.6p.85
Advance Access Published: September 2016

URL: http://dx.doi.org/10.7575/aiac.ijalel.v.5n.6p.85

\begin{abstract}
The present study is intended to determine how extensive exposure to target language mass media can affect foreign language learning and the poverty of the stimulus problem in the foreign language context. For this purpose, an EFL learner was studied for the period of one month and was asked to have extensive exposure to English language mass media only. The case was also asked to record her experience in a journal on a daily basis. The results indicated tangible improvement in her English speaking, listening, pronunciation and vocabulary but hardly any improvement on her English writing. A more profound impact was reported on the subject's four-year-old son who was not initially the focus of this study. The results suggest that considering the authentic, lengthy language input it provides, foreign language mass media can compensate for the problem of poverty of the stimulus in foreign language learning. It is concluded that formal language instruction and exposure to foreign language mass media outside the class can complement one another and promote foreign language learning on the whole. It is also evident that the impact of extensive language input varies with the age of the language learner, with young learners bearing more influence than adult learners as the effects of the critical period hypothesis.
\end{abstract}

Keywords: Poverty of the Stimulus, Mass Media, Second Language Acquisition, Foreign Language Context, Foreign Language Learning

\section{Introduction}

The poverty of the stimulus (P.O.S) argument, first proposed by Chomsky (1980), argues that the input we receive from the environment is too meager to lead to language acquisition and it is, therefore, the Language Acquisition Device that is making the language acquisition phenomenon possible. Although the plausibility of the stimulus of the poverty argument is still in debate in the field of second language acquisition (Ellis, 2008), it is clear that poor input can negatively influence foreign language learners who may never be exposed to authentic English language input. In some countries, most of the foreign language that learners are exposed to, has been simplified for their level and in many countries, foreign language instructors are non-native speakers who may have strong accents of their mother tongue or errors influencing their foreign language performance and therefore the performance of those who are taught by them.

The issue of P.O.S. has generally been discussed in literature in the field, yet the researcher failed to find any empirical studies in this area. Moreover, most of the literature on P.O.S. is concerned with first or second language acquisition, yet justice has not been done to P.O.S. in the foreign language context, perhaps as a result of lack of attention to its importance or lack of interest in the researchers of the field to revive an area of disagreement which used to be highly controversial back in the day. The current study focuses on this neglected area and pursues the answer to one question, how does extensive exposure to target language mass media as a source of rich language input affect second language learning and the problem of the poverty of the stimulus in the foreign language context?

\section{Literature Review}

\subsection{Language input}

Krashen and Terrell (1983) proposed their theory of natural approach to second language teaching in the 1980s which gave rise to the use of authentic material in the field of ELT. Although Krashen was strongly criticized for the specific terminology that he used and how he defined it, McLaughlin (1987) and Zafar (2009) for instance, the emphasis he put on input was never fully appreciated. Input is the basic area of consideration in every cognitive processing activity as it is the foundation of all knowledge to be built (Moyer, 2009). Two important aspects of input which are considered in the related literature are the quantity and quality of input.

Research has proved that the quantity of input or also referred to as length of exposure is in correlation with language proficiency. García Mayo (2003) states the final results of her study on the length of exposure and the acquisition of English as a foreign language as:" the longer the exposure to the L2, the better performance becomes" (p. 106). The quantity of input in the foreign language context is rather rudimentary especially in countries where tourism and foreign investment is not promoted. The learners may never have the opportunity to have an actual conversation with a native 
speaker or someone who does not speak their mother tongue and all people can communicate with one another using the only language spoken in the country. Communication in the foreign language that is being learned is basically limited to the hours spent in the foreign language class in non-authentic, invented situations. The language learner may not grasp the reason why the foreign language is used in the classroom with all his/her first language user classmates as there is a more powerful, more easily comprehensible source of input available, their mother tongue! The failure to realize the importance of foreign language use in the foreign language class, along with the urge and ease of first language use limits the use of the foreign language itself which is the only source of input for the language learner. This major problem with limited quantity of input is especially the issue in the foreign language learning context.

Today, EFL learners study a balanced proportion of grammar, vocabulary and the four skills artistically designed into real life tasks for the language learner, however, the language that it presented to the EFL learner has been so meticulously filtered, tailored and adapted to meet their educational needs that, at times, it has lost its natural sense. The EFL class is turning into the language learner's greenhouse and in contexts such as that of foreign language learning where the learners have very low chances of meeting native speakers outside the classroom, the language taught and spoken in the foreign language class, flawless or flawed, is simply all the foreign language input the learners receive. The non-native teacher in the foreign language classroom is yet another threat to the quality of input that the learners receive. Although a number of non-native teachers are highly-qualified and extremely proficient in the foreign language that they are teaching, there is a majority of foreign language teachers with minimum proficiency in the language they teach, however, the budget limitations of the language school demands the recruitment of less proficient, yet lower-paid teachers. Teachers with moderate proficiency in the foreign language are more likely to produce language with repeated errors which can be a poor source of input for the learners. Even if the learners do have the grammatical knowledge or access to other sources of input, the repetition of these errors can seriously threaten the quality of input that they are provided with altogether.

\subsection{Mass media as a rich source of language input}

With a narrow minority of native speakers in the foreign language context, the most natural input that is available to EFL speakers is through mass media. Mass media provide stretches of information, they are versatile and can motivate students and help them integrate their listening, reading, speaking and writing skills (Tafani, 2009). As a result of their versatility, the media can create more chances for foreign language contact.

With its abundant flood of natural language input and easy access for the majority television is the most common form of media, whether it is cable television or satellite, online television, DVDs, movies or series. A typical language class may last for one and half or two hours after which a break is necessary due to the fatigue it causes. However, the average individual can spend four hours a day watching television (Broadcasters' Audience Research Board, 2012) and we seldom hear any complaints about the viewer needing a break! Research shows that brain activity during a lecture is equal to watching television (Mazur, 2014). Thus, only attending class might not be as educationally profitable as we expect, for focus and attention is what we are after. Learners can be instructed to pay close attention to a particular structure or vocabulary family in a certain movie or television series which can result in the focused attention to language input which the language instructor desires.

Listening to tailored recordings in class may be a good exercise to test the learners' listening proficiency and help prepare for a language test yet listening to songs in the second language is not only far more enjoyable but also much more authentic. When the learners are engaged in a more interesting task, repetition and the long hours spent are no longer excruciating. On the whole, exposure to mass media can interest and therefore improve and accelerate learning. Learners can be assigned to listen to predetermined songs outside the class and transcribe as many sentences as they can.

Songs, DVDs, books and magazines are also available in the foreign language context. The internet can be another source of natural input of the foreign language, however, easy to access translations have now made it easier to get information in any language and it may be difficult for learners to limit themselves to the target language. Social networks are no exception, if the learners impose language limitations on their communications. However, since most learners join social networks to touch base with their real life friends, the language used will no longer be native-like input. The radio can also account for a source of language input, hence, it lacks the privilege of easy access, many learners in the foreign language context cannot or do not wish to tune into foreign radio stations as audiovisual sources are of greater interest.

\subsection{Related studies}

Studies conducted on mass media and language learning do not amount to an eye-catching number. The researcher believes this could be a result of the negligence to foreign language teaching and learning as most of the research in the field of language teaching has focused on second language teaching or acquisition. On the contrary, Computer-Assisted Language Learning has received worldwide attention from researchers and publishers alike. Computers and the Internet have much to offer the language learner, yet the major issue is the application. Although new versions of each program are more user-friendly, computers cannot equal to satellite or cable television in terms of versatility and ease of use. The focus on mass media in the present study is as a result of their applicability in the EFL context.

Tafani (2009) described various ways in which mass media can help students to learn a language. Bahrani and Tam (2011) studied the role of audiovisual mass media news in language learning. They emphasize the importance of redundancy of input and report that mass media news can be highly influential on the speaking proficiency of EFL 
learners. Both studies mentioned, Tafani (2009) and Bahrani and Tam (2011), highlight the role of mass media news and newspapers. The researcher of the current article believes that the news can be very informative and educational, at the same time, it contains jargons that might never be used in everyday conversations. Moreover, there is no interaction in the news. Movies, serials and even cartoons can present a more naturalistic view of the second language and culture to the learner. Especially when considering foreign language learners who may only have their imagination to contribute to their image of the foreign language environment. In a study conducted by Cowen (1984), it was concluded that Film is more influential and better recalled than conflicting text information, regardless of the order in which media appear which proves that visual media makes concepts more accessible to a person than text media and help with later recall.

\section{Materials and Methods}

The participant of this study was a female adult EFL learner from Tehran, Iran, aged 32, married and mother of a child (a son aged four years and six months). She holds a BS in accounting and had previously worked as an accountant for an international company. She is currently a stay-at-home mother. The case has studied English in an accredited EFL institute in the capital city of Iran every day for the past two years and has passed every level consecutively. She is planning to immigrate to Australia and has a strong motivation to learn English well. Unfortunately, she was unhappy with her progress in English at the beginning of the experiment. She explained that although she was well-aware of many grammar points and the definition or Persian translation of English words, she found it difficult to use them in a natural setting, for instance, when they had English-speaking guests. She also suffered from very low self-confidence in speaking English and had major problems with pronunciation and intonation. One thing that she deeply wished to do was to understand most parts of a listening task. She was worried that she had very little understanding of what she listened to in English. Teachers who had worked with the case complained that she was very weak in writing and made horrible spelling mistakes.

The case was asked to shift to English language media for a period of one month. She was told to shut down any input in her mother tongue, Persian, and turn to their English alternative. Television programs, movies, serials, DVDs, songs, books, novels and even the news had to be delivered to her in English. She was told to record her effort and her progress daily, in a journal.

The design proposed for this study was a qualitative one. A descriptive approach was adopted to analyze the data. The journal entries recorded by the case were thoroughly studied and conclusions were drawn from them. The case herself was also interviewed on several occasions (weekly and once after the completion of the experiment) for a more in-depth insight into the study. She was asked for her opinion of the experiment and the effect that she observed on her English proficiency and her performance in the EFL class.

\section{Results}

Parts of the journal entries, recorded by the case are quoted in the following. All the mistakes that she made, for instance in grammar and spelling, are also included.

May 26, 2014: "today I was listening to english song the names was <<stay with me baybe when the light go down>> and I couldn't recognise other words I heared sevral times but I couldn't understand. today I sent English massages to my husband and fotunatly he coprat me and replyed in English ansewer but I tried a lot to speak english but unluckily he became angry and all the time he said please speak persian. today for first time I spoak with my brothe English It was tribble becous of my accent and I couln't speak fuluantly without hestation. It was awfull but I continue rudly."

May 27, 2014: "I can change the chanal and watched the program or compition about losing wight it was amazing becouse I colud understand $30 \%$ but after that I saw a movi I couldn't understand anything. I spoak with my husband it was so so becouse every where I couldn't find English word or when I wanted to say s.t exited or when I had fell angry I couldn't control myself and forgot everything and use persion word and continue speak persion I have fell regret for today. Tomorrow I do my best becous I promised."

May 28, 2014: "I saw a movi I could undrstant some words becous It was cartoon as simple cartoon ... I was listning for 15 times and I can write lyrics without cheating..."

May 29, 2014: "I ordered a meal from resturant suddnly the word that first come to my mind was english word. I'm so happy becouse I think my brain start her working. today my husband and I played with matin with english speaking and matin [the participant's son] accpeted that we speak english. I couldn't speak with my husband a lot becous of my mistake we had argued with together. today I wasn't satisfied about myself."

May 30, 2014: "... we watched some cortoons (sponge bob) I could undersrand word by word not sentense that thay said. I sent e-massage to my cosin and she coprated with me and we sent a lot of english massage together. after that my son said to me pls speak english with me becous I'd like to know the cartoon. I tried to speak with him."

May 31, 2014: "today when I was in the class I tried to speak without mistak and I paied attantion to my accent. I can say 2 or 3 words with correct accent. today from 3:0 oclock until 9 clock my son and I watched cartoon. also I didnt have consentrat all the time but when I focused to the cartoon I could understand hole of sentences that they said not word by word... today we've never seen persion channals."

June 1, 2014: "I listened to the music and I saw some diffrent cartoons but I couldn't undrestand all the thing that they say I could undrestand hole of story. I speak with my husband. today I wasn't tallerent to did my program." 
June 2, 2014: "today I was listing to music a lot about 4 hours... I whispered that english song to my self. befor that when I was alon I'd like to whispered persion son but now the first songs that comes to my mind is english. every thing in my mind become english.

June 4, 2014: "today I listend to the music and...I could understand 50\% of everythings that they said they speak fastly. today I spoak pirsion, I felt sorry."

June 7, 2014: "today I saw a movi that made for childreen It was good but there is Indian peaple who she was actres and I couldn't undrestand what she saiy? I listened to music when I did exersic and I sing with him I picked up by heart. in the class I was so cearfull about my intonation but sometimes I forgot."

June 9, 2014: "today I saw a criyals it was so funny and made for childreen I could understand. 10 days ago I saw aponge bob and I learnt new vocabulary and today when my son saw it again sponge bob said that vocabulary and I was asleep and I said the meaning in my mind when I was asleep. it was wondersull for me."

June 13, 2014: "I saw movi it was good I couldn't understand every thing but I think I'm improve in english. My ear habbit to hear english song I listend to music a lot. I think I changed my lifestyle family. befor that all of things in our home were persion but now it's chang."

June 16, 2014: "... I saw cortoons with my son I complitly undrestood some cortoons."

June 17, 2014: "I saw cortoons on of them was difficult but another one were ok becous we could undrestand I think my son's languge improve and he intrested in learning english that's enough for me..."

June 19, 2014. "we saw cartoon (sponge bob) I could undrestand the story. my son recognize the world one by one it's amazing. I listend to the song. I read the magazine I found the new word it was good for me."

June 21, 2014: "today I went in my son's kindergarten and I had to speak with his manager. he speak a lot about polition and every world that comes sooner in my mind was english. sometimes I used the word. my son's teacher said matin was good at english befor but near the 15 days he complitly chang he paid attantion to english lesson more than other childreen he asked my qustion mor than other. he is so good and he tried to said the word with correct pronunciation."

June 23, 2014: "... I saw movi it was good I could undrestand but one of them was easy I undrestood easily."

June 25, 2014: "... I get more confidence with this program. I know, I need practice more but I think I get improve becouse of my confidence, my listening ... Tnx Teacher"

\section{Discussion}

In the beginning of the experiment, the case reported difficulties in carrying out the experiment. She complained that it was difficult for her to push herself and her family to limit themselves to English-language media. She noted the biggest problem to be the shift in the television programs which her son watched regularly, to English-speaking cartoons and channels. It is clearly visible from the journal entries that the case felt major progress in her listening proficiency only a short while after starting the experiment. She also reported better memory skills with English words. The most significant progress in the case's opinion, as disclosed in the interview with the researcher, was with her pronunciation. She said that the words she learned through songs and movies were carved in her memory with the correct English pronunciation in a way that she could not forget. However, very little progress was observed with the participant's spelling, words like "because", "understand", "listened" and "cartoons" were still misspelt to the end of the journal. It is worth noting that there were incidents of corrections towards the end of the journal.

One intriguing issue that the participant has mentioned in her diary entries is how English has influenced her subconscious mind during the experiment. It is assumed that the wide exposure to target language media has been able to contribute to her Inter Language improvement.

The case found the impact more profound on her four-year-old son who used to react aggressively to a change in the language of the media, but eventually found more interest in English-language cartoons and songs. The case reported extreme changes in her son's English listening, speaking and vocabulary, in a way that surprised his English teachers and school authorities. She noted that given the fact that the experiment was taken out for a one-month period only, the results were phenomenal and she wished to continue with the same trend even after the study was terminated.

\section{Conclusion}

The findings of this study suggest that extensive exposure towards media can accelerate language learning. The impact that extensive exposure to media can have on listening, speaking, pronunciation and vocabulary of the foreign language learner, has been described as phenomenal, especially in the case of the young learner. However, hardly any impact was observed on the writing skill of the participant. It is suggested that the authenticity and length of the language input offered by the mass media can compensate for the poverty of the stimulus problem in the foreign language context. The findings align with those of Tafani (2009) and Bahrani and Tam (2011) in the emphasis placed on the constructive role of media in language learning. The difference that lies in the above-mentioned studies and the study in hand lies in learning and acquisition of language. The former have basically addressed the issue of language learning and the application of mass media in the second language classroom, whereas the latter focuses on language acquisition outside the classroom and altering overall language proficiency without limiting the learner to one single setting and mandatory use of paper and pencil. 
Mass media and language acquisition was further investigated in a separate study by Bahrani, Tam and Zuraidah (2014) in which preferences of language learners in terms of audio-visual programs were investigated. One of the conclusions drawn was that the quality of language input (cartoons vs the news for instance) outshone the quantity in enhancing the proficiency of the learners. Perhaps the findings of the present study contradict these findings as the four-year-old who was exposed to cartoons and children's programs showed a more significant improvement than the adult learner exposed to movies and the news. As a result, it is suggested that the element of age is added to this area of research indicating the difference in the impact of mass media on language learning varying with age; are young learners further influenced by extensive input and adults by high quality input? It is also evident that the impact is intensified in case of exposure during the critical period as the process of second language acquisition is, then, the same as that of first language acquisition (Bialystok \& Hakuta, 1999). Therefore, especially in the case of young learners, the more extensive the language input gets, the better language learning outcomes are achieved.

It is recommended that teachers of English assign homework tasks including exposure to the media which can be both educational and entertaining and therefore, easier to maintain for a longer period of time. Once the language learner is taught how to benefit from mass media for learning purposes, they can manage without the help of a teacher which can promote learner autonomy. While watching movies and television programs and listening to English songs can first seem impossible in terms of comprehension for EFL learners, it can miraculously enhance the learner's ability to communicate in the target language with a bit of perseverance and patience. It is through extended exposure to media that EFL learners can turn their passive language knowledge into active, eradicate their pronunciation errors and get a clearer insight of the cultural and pragmatic use of the language knowledge they receive through formal instruction. A combination of formal language instruction and natural abundant input can increase learning possibilities for the EFL learner and maximize language learning opportunities. It is recommended that teachers assign tasks which entail extensive exposure to media outside the foreign language classroom to accompany the formal instruction delivered in class and to compensate for the poverty of the stimulus in the foreign language context.

\section{References}

Bahrani, T., \& Tam, S. S. (2011). The role of audiovisual mass media news in language learning. English Language Teaching, 4(2), 260-266.

Bahrani, T., Tam, S. S., \& Zuraidah M.D. (2014). authentic language input through audiovisual technology and second language acquisition. SAGE Open, 1-8.

Bialystok, E., \& Hakuta, K. (1999). Confounded age: Linguistic and cognitive factors in age differences in second anguage acquisition. In D. Birdsong (Ed.), Second language acquisition and the critical period hypothesis (pp. 161-181). Mahwah, NJ: Lawrence Erlbaum Associates.

Broadcasters' Audience Research Board. (2012). BARB establishment survey of TV homes. London: BARB.

Chomsky, N. (1980). Rules and Representations. Oxford: Basil Blackwell.

Cowen, P. S. (1984). Film and text: Order effects in recall and social inferences. Educational technology research and development, 32(3), 131-134.

Ellis, R. (2008). The Study of Second Language Acquisition. Oxford: Oxford University Press.

García Mayo, M. P. (2003). Age, length of exposure and grammaticality judgements in the acquisition of English as a foreign language. In M. P. García Mayo, \& M. L. García Lecumberri (Eds.), Age and the Acquisition of English as a foreign Language (pp. 94-114). Clevedon, Buffalo, Toronto, Sydney: Multilingual Matters.

Krashen, S. (1981). Second Language Acquisition and Second Language Learning. Oxford: Pergamon Press.

Krashen, S. D. (1985). The Input Hypothesis. Harlow: Longman.

Krashen, S. D., \& Terrell, T. D. (1983). The natural approach: Language acquisition in the classroom. San Francisco: The Alemany Press.

Mazur, E. (2014). Memorization or understanding: Are we teaching the right thing? Edulearn14. Barcelona: IATED.

McLaughlin, B. (1987). Theories of second language learning. London: Edward Arnold.

Moyer, A. (2009). Input as a critical means to an end: Quantity and quality of experience in L2 phonological attainment. In T. Piske, \& M. Young-Scholten (Eds.), Input matters in SLA (pp. 159-174). New York: Multilingual Matters.

Tafani, V. (2009). Teaching English through mass media. Acta Didactica Napocensia, 2(1), 81-96.

Zafar, M. (2009). Monitoring the 'monitor': A critique of Krashen's five hypotheses. Dhaka University Journal of Linguistics, 2(4), 139 